\title{
A TEN YEARS' STUDY OF SPONTANEOUS PNEUMOTHORAX IN A COMMUNITY \\ BY
}

\author{
N. WYNN-WILLIAMS \\ From the Bedford General Hospital
}

(RECEIVED FOR PUBLICATION MARCH 9, 1957)

Most accounts of pneumothorax have been given from large hospitals drawing selected patients from a wide area or specializing in diseases of the chest. But the incidence of pneumothorax in a community and particularly the aetiological factors concerned in an unselected series have not been investigated. In this paper every known case of pneumothorax coming under observation at the Bedford General Hospital and its attached chest clinic during a 10-year period has been collected. These cases may be divided for convenience into three main groups, "idiopathic" spontaneous pneumothorax, spontaneous pneumothorax complicating pulmonary tuberculosis, and pneumothorax complicating pyogenic infection usually of the lung.

\section{Material and Criteria of Diagnosis}

Cases of pneumothorax following frank trauma and air found in the pleural cavity after aspiration of fluid from the chest were excluded from the series. Apart from these every case of pneumothorax seen at the chest clinic and in the wards and out-patient departments of the Bedford General Hospital between January, 1947, and December, 1956, was included. The population covered was about 150,000 , and the area consists of a county town (rather over one-third of population) surrounded by small urban and rural communities. With the exception of one case confirmed at necropsy, the diagnosis was based on radiographic evidence in every patient.

\section{"Idiopathic" Spontaneous Pneumothorax}

General Findings. - Seventy-four pneumothoraces were seen in 70 patients of whom 59 were men. Four patients had bilateral pneumothoraces, and in two of them the pneumothoraces were present at the same time. The number of cases seen each year is shown in Table I and was fairly even throughout the period except that the numbers were smaller in 1947 and 1948, probably due to the radiological facilities being much less in these years. The right side was affected on 29 occasions, and the left on 45. A diagnosis was made on clinical grounds in 47 , and only after radiography in 27 . Thirty of the 70 patients were admitted to or diagnosed in hospital.

Age AND Type of ONSET.-The age at which pneumothorax occurred is set out by decades in Table II, and in the case of bilateral pneumothoraces at the date of the first pneumothorax. It was uncommon under the age of 20 , and was most frequent between 20 and 39 . Cases continued to arise right into the seventh decade in which there were 10 cases. Thirty-one (more than $40 \%$ ) were over the age of 40 . Most investigators have found

TABLE I

ANNUAL ŃUMBER OF PATIENTS WITH SPONTANEOUS PNEUMOTHORAX DIVIDED ACCORDING TO SEX AND SIDE OF PNEUMOTHORAX

\begin{tabular}{l|l|c|c|c|c}
\hline \multirow{2}{*}{ Year } & $\begin{array}{c}\text { No. of } \\
\text { Patients }\end{array}$ & Male & Female & \multicolumn{2}{|c}{ Side } \\
\cline { 2 - 5 } & & & & Right & Left \\
\hline 1947 & 4 & 3 & 1 & 3 & 1 \\
1948 & 4 & 2 & 2 & 1 & 3 \\
1949 & 6 & 6 & 0 & 3 & 3 \\
1950 & 8 & 6 & 2 & 2 & 6 \\
1951 & 6 & 4 & 2 & 2 & 4 \\
1952 & $5(1)^{*}$ & 5 & 0 & 2 & 5 \\
1953 & $7(1)$ & 4 & 3 & 3 & 5 \\
1954 & 8 & 8 & 0 & 3 & 3 \\
1955 & $6(1)$ & 5 & 1 & 4 & 11 \\
\hline 1956 & $16(1)$ & 16 & 0 & 6 & 45 \\
\hline Total & $70(4)$ & 59 & 11 & 29 & 45 \\
\hline
\end{tabular}

* The figures in brackets indicate the occurrence of a pneumothorax on the opposite side in a patient already included.

TABLE II

AGE DISTRIBUTION OF PATIENTS AND NUMBER OF PNEUMOTHORACES SHOWING TYPE OF ONSET

\begin{tabular}{|c|c|c|c|c|}
\hline \multirow{2}{*}{ Age } & \multirow{2}{*}{$\begin{array}{l}\text { No. of } \\
\text { Patients }\end{array}$} & \multirow{2}{*}{$\begin{array}{l}\text { Pneumo- } \\
\text { thoraces }\end{array}$} & \multicolumn{2}{|c|}{ Onset } \\
\hline & & & Sudden & Insidious \\
\hline $\begin{array}{cc}0-9 & . \\
10-19 & \cdots \\
20-29 & \cdots \\
30-39 & . \\
40-49 & \cdots \\
50-59 & \cdots \\
60-69 & \cdots \\
70 \text { and over }\end{array}$ & $\begin{array}{r}2 \\
6 \\
20 \\
11 \\
9 \\
11 \\
10 \\
1\end{array}$ & $\begin{array}{r}2 \\
6 \\
21 \\
11 \\
10 \\
13 \\
10 \\
1\end{array}$ & $\begin{array}{r}1 \\
4 \\
18 \\
11 \\
7 \\
7 \\
4 \\
-\end{array}$ & $\begin{array}{l}1 \\
2 \\
3 \\
0 \\
3 \\
6 \\
6 \\
1\end{array}$ \\
\hline Total .. & 70 & 74 & 52 & 22 \\
\hline
\end{tabular}


pneumothorax to be much commoner under 40 . For instance, Myers (1954) reported over 90\% under the age of 40, and Perry (1939) nearly $75 \%$. But Ehrenhaft, Taber, and Lawrence (1955) found nearly $40 \%$ of their patients to be over the age of 40 , and Crowther (1955) nearly $35 \%$. Inclusion or not of patients with obvious pulmonary disease, who more often belong to the older age groups, appears to account for these divergencies.

Fifty-two of the incidents started acutely with sudden pain or rapidly increasing shortness of breath or both. Twenty-two started insidiously without definite pain or dyspnoea. An acute onset was much commoner in patients below the age of 40 , but an insidious onset was nearly as frequent as an acute one over this age (Table II). An acute onset has regularly been reported as more common.

Size of Pneumothorax. - Twenty-two were large, 19 medium, 32 small, and one unknown. The large pneumothoraces were most commonly associated with an acute onset and were commoner in the younger age groups. In 12 patients with a history of acute onset a small pneumothorax was found, but this appeared to be due to delay in radiography and consequent re-expansion.

Treatment.-The treatment of these cases was primarily governed by the degree of dyspnoea in the initial stages. If this was distressing air was removed; otherwise natural re-expansion was allowed to take place and did so in 49 of the 74 pneumothoraces. Delay in re-expansion beyond 14 days or a previous pneumothorax were other reasons for intervention.

In 25 pneumothoraces air was removed on one or more occasions. In seven of them treatment was considered an urgent necessity; three of these were pneumothoraces under positive pressure, and four were associated with pulmonary disease which lowered the respiratory reserve to an inadequate level. In all seven, evidence of a bronchopleural fistula was present and treatment consisted in the insertion of a Foster-Carter needle or intrapleural catheter attached to an under-water seal. Complete pulmonary re-expansion was obtained except in three patients. One discharged himself from hospital and was lost sight of, one died of pneumonia and heart failure after 17 days' observation with a small pneumothorax at a negative pressure, and one died suddenly, probably of coronary thrombosis. Pleurodesis with blood was attempted in six cases. There was no recurrence in five of them, but the sixth had a further pneumothorax, and at thoracotomy a bronchiectatic lobe with cystic areas was removed. One patient developed a haemopneumothorax, bu施 made an uninterrupted recovery after a singles aspiration of about 2 pints of blood. Fluid suffi cient to cover the diaphragm developed in $1 \frac{\bar{c}}{\bar{c}}$ other patients; it was aspirated in six of them $\bar{\square}$ and found to be straw-coloured and sterile on culture.

Recently more active measures for treating $\overrightarrow{0}$ spontaneous pneumothorax have been advocated (Hughes, Kraeft, and Lowry, 1951 ; Shefts, Gil. patrick, Swindell, and Gabbard, 1954), and in this series there has been a tendency to more active treatment including the insertion of an intercostari catheter.

RECURRENCES.-Seven patients had more thanc one pneumothorax. Four of the seven had hado previous pneumothoraces, and one of them devel- oped another pneumothorax while under observa- $\infty \rho$ tion. The other three patients had single recur- 0 rences after three, 15 , and 18 months respectively. $\stackrel{\mathbb{D}}{3}$ Very varying figures have been given for the recur-o rence rate of spontaneous pneumothorax. Myers (1954) found 29 out of 100 cases with one ore more recurrences, and Ornstein and Lercher (1942) $)$ 17 cases out of 58 . On the other hand, Leachio (1945) had only seven out of 126 and Perry (1939) had four out of 85 cases. Such differences may explained by selection of cases and completenesso and duration of follow-up as well as chance in $\stackrel{2}{\square}$ relatively small series.

Follow-UP AND Prognosis.-Of the 70 patients, $\stackrel{\vec{\circ}}{3}$ 65 were followed up until the end of 1956 ; five were lost sight of. One, a woman of 27 , hado developed pulmonary tuberculosis on the same side as the pneumothorax after an interval of three $\overline{0}$ years. Eight had died, five of causes unrelated to pneumothorax. Of the other three patients one, $\frac{-}{-}$ aged 64, died suddenly six weeks after the onset of 3 . the pneumothorax. At the time the lung was wello expanded with an intercostal catheter attached to a negative pressure bottle. Death was thought to beo due to a coronary thrombosis, but the necropsy? was inconclusive. One patient aged 43 with bron-o chitis and emphysema died of pneumonia and heart failure with a small pneumothorax at a sub- $\sigma$ atmospheric pressure still present. The eighth N patient, aged 54, was being treated for heart failure N when he complained of a sudden pain in the chest $\omega$ and dyspnoea. At necropsy a pneumothorax was found.

The high death rate in this series is due to the high incidence of associated disease. There was no death among those who had no associated ${ }^{\circ}$ disease of the lungs or heart. These findings are $\mathbb{D}$ in general agreement with those of others. 
Aetiological Considerations.-There was a possible causative factor in 41 of the 70 patients. Six had bronchiectasis; one of these also had asthma. Eleven had chronic bronchitis and emphysema; three of these had asthma. Healed pulmonary tuberculosis was present in four, and histologically confirmed sarcoidosis in two, one of whom was suffering at the time from an asthmatic attack. Bullae were seen radiologically or at thoracoscopy in four, and small apical linear shadows or translucencies suggesting possible apical emphysema were seen in nine. Three patients with normal lung fields suffered from asthma; one of them was seen in status asthmaticus with a spontaneous pneumothorax. One case may have followed slight trauma to the chest wall, and one the induction of regional anaesthesia by brachial block in a patient who also had chronic bronchitis and emphysema. Although asthma is not usually regarded as a cause of spontaneous pneumothorax eight patients were asthmatics, and four of them were suffering from an attack at the onset of the pneumothorax. Twenty-six of the 29 patients with normal lung fields and no history of asthma were under the age of 40 . The demonstration of an aetiological factor in spontaneous pneumothorax seems to depend mainly on the patient's age. The high rate of concomitant disease reported here is due to over $40 \%$ of the patients being over the age of 40 .

\section{Pneumothorax Associated with Pulmonary TUBERCULOSIS}

Spontaneous pneumothorax may be associated with active pulmonary tuberculosis or inactive healed pulmonary tuberculosis. It may also develop as a complication of collapse therapy undertaken in the treatment of tuberculosis.

Six cases were observed in patients with pulmonary tuberculosis not receiving collapse therapy. In two of these the tuberculosis was active, and in both the pneumothorax was followed by a purulent tuberculous effusion. In four the tuberculosis was inactive, and these cases have been included above among the cases of "idiopathic" spontaneous pneumothorax. Considering the large number of patients with healed tuberculous lesions, pneumothorax is an uncommon complication of this type of disease.

Pneumothorax Complicating Treatment for Pulmonary Tuberculosis.-As a complication of artificial pneumothorax (A.P.) spontaneous pneumothorax falls into two groups. The first follows an apparently normal refill within a few hours. It is benign in course and is not followed by the development of effusion. The second is a serious accident due to the tearing of an adhesion or to the rupture of a cavity or tuberculous focus into the pleural cavity. It is followed by the development of effusion and usually a bronchopleural fistula. During the period about 17,286 refills were given to 155 patients. Spontaneous pneumothorax of the benign type was detected in 10 patients. It happened on more than one occasion in three patients, and in one patient who had a left and later a right pneumothorax it occurred on both sides. Spontaneous pneumothorax of the more serious type occurred in one patient. One patient developed a spontaneous pneumothorax into the pleural space occupied by an effusion remaining after cessation of artificial pneumothorax.

Two patients with bilateral pulmonary tuberculosis who were being treated by artificial pneumoperitoneum developed right spontaneous pneumothoraces. During the period about 22,500 artificial pneumoperitoneum refills were given to 235 patients. This rare complication occurs predominantly on the right side; it has been reviewed by Lumsden (1949) and Crofts (1954).

\section{Pneumothorax Accompanying Pyogenic INFECTION}

The cases of pneumothorax associated with pyogenic infection could be divided into three main groups: those following pulmonary infection in children, those following pulmonary infection in adults, and those secondary to adjacent sepsis.

Following Pulmonary Infection in Children.Four children, two boys and two girls, were seen who developed pneumothorax associated with a respiratory illness that was clinically and radiologically typical of staphylococcal pneumonia, though Staphylococcus aureus was isolated from only three of them; the youngest was 3 weeks old and the oldest was 7 montins. Two of these children had pyopneumothoraces, and two had tension pneumothoraces. All recovered with treatment. Staphylococcal pneumonia giving rise to similar complications was described by MacGregor (1936) and Clemens and Weens (1942).

Following Pulmonary Infection in Adults.There were six cases all of which presented with a pyopneumothorax; three complicated pneumonia, two pulmonary abscess, and one secondary carcinoma. One pyopneumothorax that followed pneumonia in a woman aged 76 responded to continuous drainage with an intercostal catheter, but the patient died of heart failure and senility six weeks later. The other 
patients recovered with appropriate treatment except for the one with secondary carcinoma. These cases of pyopneumothorax followed diseases well known to be complicated by pyopneumothorax (Tubbs, 1952). They invite no special comment except to observe that it is not a common complication.

Secondary to Adjacent Sepsis.-One case of this type was seen. A man aged 59 with a chronic gastric ulcer was admitted to hospital with severe haematemesis. A subphrenic abscess developed and burst through the diaphragm into the left pleural cavity. Continuous intercostal drainage was carried out, but death followed shortly. Necropsy confirmed the diagnosis. Perforation of the diaphragm and the formation of pyopneumothorax is a rare complication of subphrenic abscess. Ochsner and DeBakey (1938) found three instances of pneumothorax among 1,380 patients with subphrenic abscess whilst pyopneumothorax was also noted as a complication by Harley (1949).

\section{Discussion}

The earlier literature on spontaneous pneumothorax was very completely reviewed by Emerson in 1903. He showed that, though known to accompany many pulmonary diseases, spontaneous pneumothorax most usually was thought to be a complication of pulmonary tuberculosis. This opinion was held until Kjaergaard (1932) collected 51 patients with pneumothorax only one of whom developed pulmonary tuberculosis. This paper led to the conception of "idiopathic" spontaneous pneumothorax in the otherwise healthy. Since that time the publication of numerous cases and the increasing use of radiography have confirmed the opinion that this type of pneumothorax is fairly common. Its incidence within a community is not certainly known. Estimates of its frequency vary. Perry (1939) thought it uncommon. Melrose (1950), of similar opinion, found that it constituted $0.032 \%$ of patients admitted to a large hospital in Glasgow. Crowther (1955), dealing with out-patients and in-patients, including a hospital for chest diseases, thought it fairly rare, but Myers (1954), reviewing out-patients only, thought it much more common.

The annual incidence of "idiopathic" spontaneous pneumothorax in this area has varied little except that in 1956 it was double that of any preceding year. No cause was found for this, and it was probably due to chance. As the proportion of cases diagnosed with an insidious onset was high $(30 \%)$, and this type of pneumo- thorax is the more likely to be overlooked, it is $\stackrel{\vec{F}}{\vec{P}}$ probable that the majority of cases occurring in the area were recognized except in 1947 and 1948 을 when radiographic facilities were inadequate. The $\frac{\bar{\rho}}{\partial}$ figures suggest that "idiopathic" spontaneous $\stackrel{\square}{\unrhd}$ pneumothorax is a moderately common disease. The age of incidence in these patients is higher $\vec{\circ}$

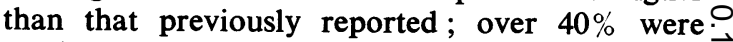
aged 40 or more. The proportion of those with $\vec{\omega}$ an insidious onset was also higher in this older $\stackrel{\circ}{\circ}$ age group. It was only in this group of patients $\vec{x}$ that death occurred and might be attributed at $\vec{N}$ least in part to the pneumothorax. Moreover, $\stackrel{\sim}{\omega}$ patients causing anxiety and requiring urgenti treatment were with two exceptions in this group. OJ Diminished cardio-respiratory reserve was clearly음 the cause of this difference in prognosis.

Most of the cases associated with pulmonary $\overrightarrow{\mathbb{D}}$ tuberculosis arose as a complication of collapse therapy. Owing to the decline in popularity of $\frac{\mathbb{}}{3}$ this form of treatment such cases will be uncommon in the future. Spontaneous pneumothorax complicating active pulmonary tuberculosis with- $\overrightarrow{0}$ out collapse therapy was seen only twice. It must. now be judged a rare cause of pneumothora 8 , although there is no doubt that it was common the past (Biach, 1880 ; West, 1884 ; Perry, 1939)

Pneumothorax following pyogenic infection of the lung or adjacent structures was uncommon $\stackrel{\square}{\perp}$ except as a complication of staphylococcal pneu- $\overrightarrow{\vec{P}}$ monia in young children. Pneumothorax or pyo- $\frac{0}{3}$ pneumothorax arose in $38 \%$ of the cases of $\vec{F}$ staphylococcal pneumonia described by Kanof, Epstein, Kramer, and Mauss (1953) and in $32 \%$ of the series of Wallman, Godfrey, and Watson (1955). If a diagnosis based upon a typical radiological and clinical picture is allowed, its frequency $\frac{0}{0}$ in this area appears to be about the same.

\section{SUMMARY}

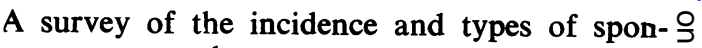
taneous pneumothorax seen at a general hospi- $\rightarrow$ tal and its attached chest clinic has been made. The population covered was about 150,000 and $\bar{N}$ the period from 1947 to 1956 inclusive. The cases ${ }^{\circ}$ of pneumothorax were divided into three sections $N$ for convenience.

"Idiopathic" spontaneous pneumothorax was seen in 70 patients in four of whom it was bi-co lateral. Thirty-one patients were aged 40 or over. $\bar{\varnothing}$ In 41 an aetiological factor was detected. Only $\stackrel{\oplus}{+}$ one patient developed pulmonary tuberculosis, $\frac{T}{T}$ and this appeared after an interval of three years. $\frac{0}{P}$ Three deaths were certainly in part due to the pneumothorax. 
Spontaneous pneumothorax associated with tuberculosis was found to be most often a complication of artificial pneumothorax or artificial pneumoperitoneum. Apart from this, only two cases were seen with active pulmonary tuberculosis, and four with inactive pulmonary tuberculosis.

Spontaneous pneumothorax accompanying pyogenic infection of the lung was uncommon. It followed staphylococcal pneumonia in infants (4), pneumonia (3), pulmonary abscess (2), secondary carcinoma of the lung (1), and subphrenic abscess (1).

\section{REFERENCES}

Biach, A. (1880). Wien. med. Wschr., 30, 6.

Clemens, H. H., and Weens, H. S. (1942). J. Pediat., 20, 281.

Crofts, N. F. (1954). Thorax, 9, 226.

Crowther, J. S. (1955). Tubercle (Lond.), 36, 265.
Ehrenhaft, J. L., Taber, R. E., and Lawrence, M. S. (1955). Amer. Rev. Tuberc., 72, 801.

Emerson, C. P. (1903). Johns Hopk. Hosp. Rep., 11, 1.

Harley, H. R. S. (1949). Thorax, 4, 1.

Hughes, F. A., Kraeft, N. H., and Lowry, C. C. (1951). J. Amer. med. Ass., 146, 244.

Kanof, A., Epstein, B., Kramer, B., and Mauss, I. (1953). Pediatrics, $11,385$.

Kjaergaard, H. (1932). Acta med. scand., Suppl. 43.

Leach, J. E. (1945). Arch. intern. Med., 76, 264.

Lumsden, E. G. S. (1949). Thorax, 4, 147.

MacGregor, A. R. (1936). Arch. Dis. Childh.,11, 195.

Melrose, A. G. (1950). Glasg. med. J., 31, 263.

Myers, J. A. (1954). Dis. Chest, 26, 420.

Ochsner, A., and DeBakey, M. (1938). Int. Abstr. Surg., 66, 426. Ornstein, G. G., and Lercher, L. (1942). Quart. Bull. Sea View Hosp., 7, 149.

Perry, K. M. A. (1939). Quart. J. Med., 8, 1.

Shefts, L. M., Gilpatrick,C., Swindell, H., and Gabbard, J. G. (1954). Dis. Chest, 26, 273.

Tubbs, O. (1952). In Marshall, G., and Perry, K. M. A., Diseases of the Chest, vol. 2, p. 18. Butterworth, London.

Wallman, I. S., Godfrey, R. C., and Watson, J. R. H. (1955). Brit. med. J., 2, 1423.

West, S. (1884). Lancet, 1, 791. 